\title{
Etiologia e possíveis fontes de inóculo para a ocorrência da podridão de miniestacas de acácia-negra
}

\author{
Izabela Moura Duin ${ }^{1}$; Antonio Rioyei Higa ${ }^{1}$; Álvaro Figueredo dos Santos²; Thiare Aparecida do Vale Coelho ${ }^{1}$; \\ Eduardo Henrique Rezende ${ }^{1}$; Celso Garcia Auer ${ }^{2}$
}

${ }^{1}$ Programa de Pós-graduação em Engenharia Florestal, Universidade Federal do Paraná, Curitiba, PR, Brasil. ${ }^{2}$ Embrapa Florestas, CP 319, 83411000, Colombo, PR, Brasil.

Autor para correspondência. Celso Garcia Auer (celso.auer@embrapa.br).

Data de chegada: 19/02/2017. Aceito para publicação em: 20/06/2017.

$10.1590 / 0100-5405 / 174647$

\section{RESUMO}

Duin, I.M.; Higa, A.R.; Santos, A.F. dos; Coelho, T.A.V.; Rezende, E.H.; Auer, C.G. Etiologia e possíveis fontes de inóculo para a ocorrência da podridão de miniestacas de acácia-negra. Summa Phytopathologica, v.43, n.4, p.297-302, 2017.

Acacia mearnsii De Wild. é cultivada no Brasil para produção de tanino, celulose e energia. Atualmente, plantios clonais estão sendo estabelecidos, mas um dos fatores limitantes à produção de mudas é a ocorrência de podridão de miniestacas. Este estudo teve por objetivo avaliar a podridão de miniestacas de acácia-negra em três clones comerciais e determinar os agentes causais associados, em Triunfo/RS. Os materiais analisados foram miniestacas com podridão; brotações de minijardim aparentemente sadias; brotações com lesões escuras; substrato utilizado para o enraizamento das miniestacas; água utilizada para a irrigação; minicepas doentes; areia proveniente dos canaletões dos minijardins; tubetes; e britas provenientes da estufa. As coletas foram efetuadas em setembro/2015 e março/2016. Para detecção de fungos, utilizou-se os métodos de isolamento direto e isolamento indireto, diluição em série, teste com isca e plaqueamento de resíduos. Calonectria polizzii e Neopestalotiopsis clavispora são os agentes causais da podridão de miniestacas de acácia-negra. Brotações assintomáticas, tubetes usados, piso da casa de vegetação e substrato usado podem ser fontes de inóculo.

Palavras-chave: Acacia mearnsii, Calonectria, doença, propagação vegetativa.

ABSTRACT

Duin, I.M.; Higa, A.R.; Santos, A.F. dos; Coelho, T.A.V.; Rezende, E.H.; Auer, C.G. Etiology and possible inoculum sources for the occurrence of rot in black wattle minicuttings. Summa Phytopathologica, v.43, n.4, p.297-302, 2017.

Acacia mearnsii De Wild. is cultivated in Brazil for tannin, cellulose and energy production. Currently, clonal plantations have been established, but one of the limiting factors for seedling production is the occurrence of rot in minicuttings. This study aimed to evaluate rot in black wattle minicuttings in three commercial clones and to determine the associated causal agents in Triunfo/RS. The analyzed materials were rotten minicuttings, apparently healthy clonal minigarden sprouts; sprouts with dark lesions; substrate used for minicutting rooting; water used for irrigation; diseased ministumps; sand from clonal minigarden; plastic tubes; and cracked stones from the greenhouse floor. Samples were collected in September/2015 and March/2016. For detection of fungi, the used methods were direct isolation and indirect isolation, serial dilution, bait test and plating of residues. Calonectria polizzii and Neopestalotiopsis clavispora are the causal agents of rot in minicuttings. Asymptomatic sprouts, plastic tubes, greenhouse floor and the used substrate can be inoculum sources.

Keywords: Acacia mearnsii, Calonectria, disease, vegetative propagation.

Acacia mearnsii De Wild., conhecida como acácia-negra é uma espécie pertencente à família Fabaceae, considerada excelente para florestamento, devido ao seu rápido crescimento e aproveitamento integral da madeira $(14,19)$. Grande parte do cultivo de acácia-negra ainda é estabelecido a partir de mudas produzidas por sementes (10). Visando contornar os problemas oriundos da produção de mudas seminais, a utilização de técnicas de propagação vegetativa é utilizada correntemente para essa espécie (2).

A fitossanidade é importante na produção de mudas florestais, tendo em vista a ocorrência de doenças em todas as etapas do processo produtivo, por sementes ou estaquia (13). O sucesso no enraizamento relaciona-se diretamente com a sanidade das estacas.

A podridão de estacas e miniestacas pode ocorrer na produção de mudas clonais de eucalipto (2). Em acácia-negra, a mesma doença vem sendo detectada com poucas informações a respeito de seus impactos na produção de mudas clonais. Sendo assim, o objetivo desse trabalho foi avaliar a podridão de miniestacas de $A$. mearnsii em três clones em um viveiro comercial, testar a patogenicidade dos principais fungos encontrados e determinar as principais fontes de inóculo dos fungos associados.

\section{MATERIAL E MÉTODOS}

Amostragem da podridão de miniestacas e fontes de inóculo no viveiro

As coletas de plantas sintomáticas, caracterizadas por podridão basal ou podridão mediana (Figura 1), foram realizadas em estufa com bandejas suspensas, em setembro/2015 ( $1^{\text {a }}$ coleta) e março/2016 ( $2^{\mathrm{a}}$ coleta), no município de Triunfo/RS. Três clones comerciais 


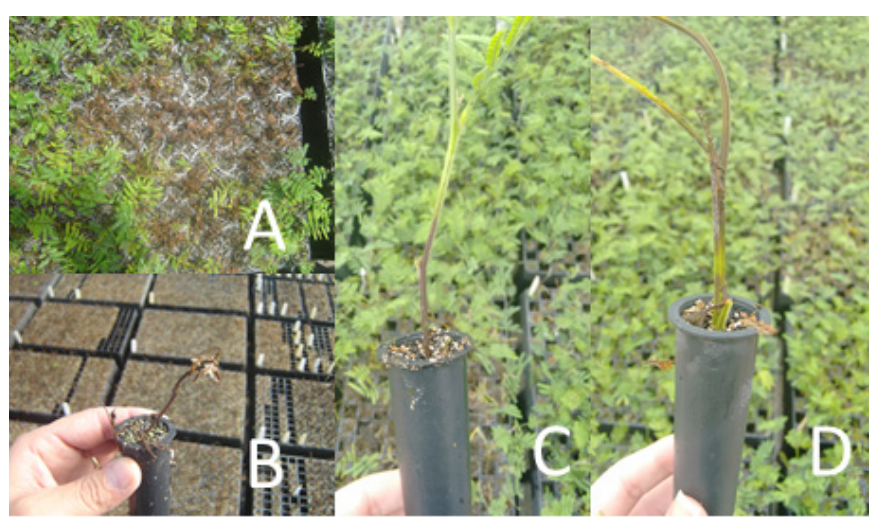

Figura 1. Mortalidade de miniestacas de acácia-negra em casa de vegetação. A: Mortalidade em reboleira; B: Miniestaca morta; C: Podridão basal; D: Podridão mediana.

foram selecionados (clone 1, clone 2 e clone 3 ). Na primeira coleta foram amostradas 300 miniestacas por clone; na segunda coleta 300 miniestacas dos clones 1 e 2, e somente 200 miniestacas do clone 3. Para a realização das coletas, toda a estufa foi percorrida, para a coleta das miniestacas sintomáticas ao acaso, as quais foram embaladas em sacos plásticos limpos, identificadas e levadas para análise no laboratório.

\section{Isolamento dos fungos}

Os fungos foram isolados de forma direta e indireta. Para o isolamento direto, as minicepas foram mantidas em câmara úmida por sete dias. $\mathrm{O}$ isolamento indireto foi realizado por meio da desinfestação de fragmentos da região de transição entre tecido necrosado e sadio. Os fragmentos foram imersos em álcool $70 \%$ por $30 \mathrm{~s}$ e hipoclorito de sódio $1 \%$ por 1 min e transferidos para placas de Petri contendo meio BDA (Batata-Dextrose-Ágar). As placas contendo os fragmentos foram incubados em câmara B.O.D, no escuro a $24^{\circ} \mathrm{C}$, até a formação de colônias. As culturas fúngicas obtidas foram repicadas para placas com meio BDA, incubadas em câmara B.O.D., no escuro a $24{ }^{\circ} \mathrm{C}$, para obtenção de cultura pura dos fungos. Calculou-se o intervalo de confiança (4), ao nível de $5 \%$, para os valores de frequência de colônias de fungos da primeira e segunda coleta.

\section{Identificação dos fungos isolados}

Lâminas foram montadas com estruturas reprodutivas, em corante de Amann, e observadas em microscópio de luz para a identificação ao nível de gênero, com o auxílio da literatura de Micologia e Patologia Florestal (6). Para a identificação molecular das espécies fúngicas, foi realizado o sequenciamento dos isolados e comparação com sequências depositadas no GenBank. O sequenciamento dos isolados foi realizado no Laboratório de Patologia Florestal da Universidade Federal de Lavras e no Laboratório de Microbiologia e Biologia Molecular (LABMICRO) da Universidade Federal do Paraná.

\section{Teste de patogenicidade}

Testou-se a patogenicidade dos fungos que apresentaram maior incidência em associação com a podridão de miniestacas de acácianegra, baseando-se em Vitti et al. (24). A inoculação foi realizada por meio de discos de sete $\mathrm{mm}$ de diâmetro contendo micélio dos fungos crescidos em meio BDA por sete dias, em B.O.D. a $24 \pm 2{ }^{\circ} \mathrm{C}$, no escuro, na base das miniestacas. Na preparação das miniestacas, estas foram desinfestadas superficialmente com álcool $70 \%$ por $30 \mathrm{~s}$ e hipoclorito de sódio $1 \%$ por 1 min e inoculou-se 24 miniestacas/isolado. Como tratamento testemunha, as miniestacas receberam discos de meio BDA. Depois, as miniestacas inoculadas foram incubadas em caixas gerbox com papel mata-borrão umedecido, mantidos sob luz fluorescente contínua, em condições de ambiente, por sete dias. A avaliação da doença foi realizada por meio da mensuração do comprimento da lesão, com o auxílio de paquímetro. Posteriormente, os fungos foram reisolados para meio BDA.

Os dados de patogenicidade foram submetidos ao teste de homogeneidade de variâncias de Bartlett, análise de variância (ANOVA) e comparou-se as médias pelo teste de Tukey a $5 \%$, por meio do programa ASSISTAT (21).

\section{Avaliação de fontes de inóculo de patógenos}

A análise das prováveis fontes de inóculo foi iniciada com a coleta de minicepas doentes dos jardins clonais; de brotações aparentemente sadias; de brotações com lesões escuras; de amostras do substrato utilizado para o enraizamento das miniestacas (novo e usado); da água utilizada para a irrigação; da areia proveniente dos canaletões dos minijardins; de tubetes e de britas provenientes da estufa. As amostras foram embaladas em sacos plásticos limpos, lacrados, identificados, levados ao laboratório e mantidas em geladeira no máximo por dois dias, antes do processamento.

Cinco minicepas doentes do minijardim clonal do viveiro foram coletadas, ao acaso, nos canaletões, para isolamento direto. Fragmentos de minicepas foram separados em duas porções: ápice (região de coleta de brotações) e do caule (parte basal); as raízes não foram consideradas.

Brotações assintomáticas foram coletadas ao acaso no minijardim clonal e isoladas pelo método direto. Brotações com lesões escuras, coletadas no minijardim clonal, onde se verificou a ocorrência do sintoma, foram isoladas pelo método indireto em meio BDA. Coletou-se 50 brotações assintomáticas e 15 brotações com lesões escuras.

O substrato novo foi coletado diretamente de embalagens ainda fechadas, armazenadas em galpão do viveiro, de onde coletou-se cinco amostras. Para isolar os fungos do substrato, utilizou-se a técnica de diluição em série descrita em Mello et al. (16). Diluiu-se $10 \mathrm{~g}$ de substrato em $90 \mathrm{~mL}$ de água, consistindo na primeira diluição, a qual passou por processo de agitação manual e a seguir, espalhou-se $100 \mu \mathrm{L}$ da diluição na superfície de placas de Petri contendo meio de Martin (5 g de peptona; $0,5 \mathrm{~g}$ de $\mathrm{MgSO}_{4} .7 \mathrm{H}_{2} \mathrm{O} ; 1 \mathrm{~g}$ de $\mathrm{K}_{2} \mathrm{HPO}_{4} ; 10 \mathrm{~mL}$ de solução de rosa bengala na concentração de $1: 300 ; 30 \mathrm{mg}$ de sulfato de estreptomicina; $10 \mathrm{~g}$ de dextrose; e $20 \mathrm{~g}$ de ágar-ágar para $1000 \mathrm{~mL}$ de água ultrapurificada). Da primeira diluição foram retirados $1 \mathrm{~mL}$ e diluídos em $9 \mathrm{~mL}$ de água, sendo essa a segunda diluição. O mesmo procedimento foi empregado sucessivamente para completar as séries de diluições: 1:10, 1:100, 1:1.000 e 1:10.000. De cada diluição foram feitos três plaqueamentos (repetições). As placas foram incubadas em câmara B.O.D., no escuro, $24{ }^{\circ} \mathrm{C}$, até a formação de colônias. Após esse período, fez-se a avaliação dos fungos presentes.

Além da diluição em série, realizou-se também o teste de isca com folhas de Eucalyptus benthamii Maiden e mamona (Ricinus communis L.) para verificar a presença de Calonectria sp. no substrato $(1 ; 11)$. Nesse teste utilizou-se dois tipos de substrato: substrato novo e substrato usado. O substrato usado foi retirado diretamente de tubetes com podridão de miniestacas. Coletou-se cinco amostras de cada tipo, cada amostra composta pelo conteúdo de cinco tubetes. O teste foi implantado em caixas gerbox com duas folhas de mata-borrão esterilizadas em autoclave e umedecidas com água ultrapurificada estéril. As amostras de substrato foram umedecidas com água ultrapurificada estéril e colocadas sobre as folhas, sendo o limbo da 
folha perfurado para a liberação da enzima estimulante ao fungo. $\mathrm{O}$ material permaneceu em câmara úmida em estante com luz fluorescente contínua e condições de laboratório por cinco dias.

A detecção de patógenos na água de irrigação e na areia foi realizada por meio da diluição em série, com os mesmos procedimentos descritos acima. A água foi coletada do reservatório que abastece o viveiro e dos bicos da irrigação no interior da estufa, coletando-se três amostras de cada situação. Cinco amostras de areia foram coletadas nos locais onde foram retiradas as minicepas doentes nos minijardins clonais.

Avaliou-se a presença de fungos em tubetes usados (tubetes coletados logo após a produção de mudas clonais ou com podridão de miniestacas) e tubetes lavados (tubetes lavados em água quente, sob alta pressão). Os tubetes usados foram os mesmos esvaziados para coleta do substrato usado; os tubetes lavados foram coletados aleatoriamente logo após a lavagem, coletando-se nove tubetes de cada situação. A metodologia consistiu na lavagem de tubetes em copo de Béquer com 20 $\mathrm{mL}$ de água ultrapurificada, esterilizados por autoclavagem. Os tubetes foram lavados com o auxílio de uma escova de plástico previamente esterilizada por $1 \mathrm{~min}$ em hipoclorito de sódio $1 \%$ e enxaguada em água estéril. A partir da solução da lavagem, alíquotas foram coletadas com micropipeta em doses de 10 e $100 \mu \mathrm{L}$ da diluição e espalhadas na superfície de placas de Petri contendo meio de Martin. Foram utilizados nove tubetes de cada tratamento (usados e lavados), cada diluição teve três repetições (placas). As placas foram incubadas conforme descrito para o isolamento de fungos do substrato.

Para a análise da presença de patógenos em britas, sob mesas suspensas da casa de vegetação com presença de reboleiras de podridão de miniestacas, coletou-se três amostras. De cada amostra, pesou-se $10 \mathrm{~g}$ que foram lavadas em $90 \mathrm{~mL}$ de água ultrapurificada esterilizada. Posteriormente, a solução foi passada em peneira plástica esterilizada para a separação dos resíduos maiores. Espalhou-se alíquotas de $10 \mathrm{e}$ $100 \mu \mathrm{L}$ da diluição na superfície de placas de Petri contendo meio de Martin. De cada diluição realizou-se três repetições (placas). As placas foram incubadas conforme descrito para o isolamento de fungos do substrato.

\section{RESULTADOS E DISCUSSÃO}

Fungos presentes em miniestacas de acácia-negra com podridão Nove gêneros Botryosphaeria, Calonectria, Fusarium, Clonostachys, Graphium, Monilia, Monochaetia, Pestalotiopsis, Coniella e outros não identificados foram isolados da primeira coleta. Calonectria sp. foi o fungo que apresentou maior incidência média $(69,7 \%)$ para todos os clones (Tabela 1), seguido por Clonostachys sp. (12,5\%), Botryosphaeria sp. (5,4\%), Pestalotiopsis sp. (5,2\%) e Fusarium sp. (2,1\%).

$\mathrm{Na}$ segunda coleta, foram isolados oito gêneros Aspergillus, Colletotrichum, Calonectria, Fusarium, Clonostachys, Pestalotiopsis, Rhizoctonia, Trichoderma e outros não identificados. Novamente, Calonectria sp. foi o fungo com maior incidência média (76\%) em todos os clones (Tabela 1), seguido por Clonostachys sp. (7,5\%), Colletotrichum sp. (4,4\%), Rhizoctonia sp. (4,3\%) e Fusarium sp. $(1,9 \%)$.

Fungos do gênero Cylindrocladium (= Calonectria) são conhecidos como patógenos de Eucalyptus e Pinus causando tombamento de plântulas, podridão de estacas, estrangulamento do caule, podridão de raízes e, no caso de Eucalyptus, também a ocorrência de manchas foliares (4). Em eucalipto, as espécies C. candelabrum Viégas, $C$. scoparium Morgan, C. gracile (Bugn.) Boesew. (=C. clavatum Hodges \& May), C. parasiticum Crous, Wingfield \& Alfenas, C. pteridis F.A. Wolf e C. ovatum El-Gholl (2) e C. ilicicola Boedijn \& Reitsma (7) são causadoras de podridão de estacas no Brasil. Em Pinus, Calonectria brachiatica L. Lombard, M.J. Wingf. \& Crous e Calonectria brassicae Pamwar \& Bohra (anamorfos de Cylindrocladium spp.) foram associados a podridão de estacas enraizadas de Pinus maximinoi e $P$. tecunumanii, na Colômbia (17).

Além de Calonectria, outros patógenos primários são encontrados em estacas mortas de eucalipto como Fusarium spp. e Rhizoctonia solani Kuhn e secundários como Colletotrichum spp. (24) e Botryosphaeria ribis Grossenb. \& Duggar (5). Fungos desses gêneros também foram encontrados em associação com a podridão de miniestacas.

Tabela 1. Fungos isolados de miniestacas de três clones de acácia-negra em duas épocas de coleta, Triunfo/RS.

\begin{tabular}{|c|c|c|c|c|c|c|c|c|}
\hline \multirow{3}{*}{ ISOLADO } & \multicolumn{8}{|c|}{ REISOLAMENTO (\%) } \\
\hline & \multicolumn{4}{|c|}{ SETEMBRO/2015 } & \multicolumn{4}{|c|}{ MARÇO/2016 } \\
\hline & CLONE 1 & CLONE 2 & CLONE 3 & MÉDIA & CLONE 1 & CLONE 2 & CLONE 3 & MÉDIA \\
\hline Calonectria sp. & $76,1 \pm 4,8^{(1)}$ & $37,3 \pm 5,2$ & $95,7 \pm 2,3$ & 69,7 & $73,5 \pm 6,1$ & $78,8 \pm 4,5$ & $75,7 \pm 5$ & 76 \\
\hline Clonostachys sp. & $7,2 \pm 2,9$ & $28,6 \pm 4,9$ & $1,7 \pm 1,5$ & 12,5 & $9,8 \pm 4,1$ & $9,1 \pm 3,1$ & $3,5 \pm 2,1$ & 7,5 \\
\hline Botryosphaeria sp. & $6,2 \pm 2,7$ & $9,3 \pm 3,1$ & $0,7 \pm 0,9$ & 5,4 & - & - & - & - \\
\hline Colletotrichum sp. & - & - & - & - & $5,9 \pm 3,2$ & $2,5 \pm 1,7$ & $4,9 \pm 2,5$ & 4,4 \\
\hline Rhizoctonia sp. & - & - & - & - & $7,8 \pm 3,7$ & $4,1 \pm 2,2$ & $1,0 \pm 1,2$ & 4,3 \\
\hline Pestalotiopsis sp. & $2,6 \pm 1,8$ & $11,7 \pm 3,5$ & $1,3 \pm 1,3$ & 5,2 & - & - & $1,4 \pm 1,4$ & 1,4 \\
\hline Fusarium sp. & - & $2,1 \pm 1,5$ & - & 2,1 & $1,0 \pm 1,4$ & $0,9 \pm 1,1$ & $3,8 \pm 2,2$ & 1,9 \\
\hline Coniella petrakii & $1,0 \pm 1,1$ & - & - & 1 & - & - & - & - \\
\hline Graphium sp. & - & $0,3 \pm 0,6$ & - & 0,3 & - & - & - & - \\
\hline Monilia sp. & - & $0,3 \pm 0,6$ & - & 0,3 & - & - & - & - \\
\hline Monochaetia sp. & - & $0,3 \pm 0,6$ & - & 0,3 & - & - & - & - \\
\hline Aspergillus sp. & - & - & - & - & - & $0,3 \pm 0,6$ & - & 0,3 \\
\hline Trichoderma sp. & - & - & - & - & - & $0,3 \pm 0,6$ & - & 0,3 \\
\hline Fungos não identificados & $7 \pm 2,8$ & $9,9 \pm 3,2$ & $0,7 \pm 0,9$ & 5,9 & $2 \pm 1,9$ & $4,1 \pm 2,2$ & $9,7 \pm 3,4$ & 5,3 \\
\hline
\end{tabular}

${ }^{(1)}$ Intervalo de confiança ao nível de $\mathrm{p}<0,05$. 
Na segunda coleta, detectou-se Rhizoctonia sp. em todos os clones de acácia-negra (Tabela 1). Rhizoctonia solani foi relatada como agente causal da podridão de miniestacas enraizadas de Pinus caribaea, $P$. tecunumanii e híbridos entre essas duas espécies (12) e Rhizoctonia sp. com a podridão de miniestacas em $E$. benthamii (20) demonstrando a sua associação com espécies florestais.

Uma espécie de Coniella isolada somente no clone 1 foi identificada como Coniella petrakii B. Sutton (23), porém sua associação com a podridão de miniestacas é incerta. Este fungo foi encontrado em árvores de acácia-negra com gomose por Sotta \& Auer (22). Com relação a Pestalotiopsis sp., não foram encontrados relatos de sua ocorrência associada com podridão de miniestacas em espécies florestais.

Vários fungos secundários foram detectados em miniestacas, cuja presença poderia ser explicada por sua ação saprofítica, em tecidos doentes, senescentes ou injuriados $(9,11)$. Dentre esses, Clonostachys sp. e Trichoderma sp., isolados de miniestacas doentes, devem estar atuando como hiperparasitas (15) nos patógenos.

Verificou-se também relação dos fungos com as épocas de coleta: época fria (setembro/2015) e quente (março/2016). Na primeira coleta, observou-se a ocorrência de Botryosphaeria sp., Coniella petrakii, Graphium sp., Monilia sp. e Monochaetia sp. e na segunda coleta Aspergillus sp., Colletotrichum sp., Rhizoctonia sp. e Trichoderma sp. Nas duas épocas, ocorreu Pestalotiopsis sp., porém com maior incidência na época fria e somente em um clone na época quente. As frequências médias de Fusarium sp. foram próximas, em todos os clones em março/2016 e somente em um clone em setembro/2015. Com relação a Calonectria sp. e Clonostachys sp. não houve distinção entre as épocas, ocorrendo em alta frequência nas duas amostragens. No caso de Calonectria, resultado similar foi relatado por Cabel (8) em miniestacas de eucalipto em casa de vegetação, no Rio Grande do Sul. Ferreira (11) considerou que a temperatura e umidade elevada no interior da casa de vegetação e injúrias operacionais, favorecem a atuação de fungos causadores de lesões ou apodrecimento de estacas.

\section{Patogenicidade de fungos em miniestacas de acácia-negra}

Os isolados sequenciados e testados foram Calonectria polizzii L. Lombard, Crous \& M.J. Wingf. (Acesso GenBank KY984058), Fusarium sp. (não depositado no GenBank), Fusarium oxysporum Schltdl (acessos GenBank - KY810792 e KY810793), Neopestalotiopsis clavispora (G.F. Atk.) Maharachch., K.D. Hyde \& Crous. (Acesso GenBank - KY810807) e Rhizoctonia solani Kuhn (acesso GenBank - KY810803). Os isolados denominados como Calonectria sp. foram renomeados para $C$. polizzii.

Nas miniestacas inoculadas com $C$. polizzii e $N$. clavispora as lesões progrediram, enquanto que nas inoculadas com Fusarium spp. e $R$. solani, ocorreu crescimento epifítico e as lesões ocorreram somente na base da miniestaca. Esse crescimento epifítico de $R$. solani foi constatado para hastes de eucalipto (7). Sendo assim, foi possível avaliar o comprimento da lesão induzidas por $C$. polizzii e $N$. clavispora . Fusarium spp. e $R$. solani não foram considerados patogênicos. Resultado diverso foi encontrado por Carvalho et al. (9) em estacas de eucalipto, que comprovaram a patogenicidade de C. scoparium, $C$. clavatum, e também de Rhizoctonia spp. e Fusarium spp.

Houve recuperação de $C$. polizzii e $N$. clavispora, cujas frequências variaram de 71 a $97 \%$ (Tabela 2). As miniestacas inoculadas exibiram os mesmos sintomas constatados no viveiro em Triunfo/RS, na forma de lesões escuras e podridão da base e as testemunhas não tinham sintomas (Figura 2). Desse modo, C. polizzii e N. clavispora foram considerados agentes causais da podridão de miniestacas.

Quanto ao tamanho das lesões, houve diferença significativa entre clones e isolados (Tabela 2). O clone 3 foi mais suscetível, provavelmente com menor enraizamento no viveiro. Os clones foram mais suscetíveis ao ataque de $C$. polizzii do que $N$. clavispora.

Diferença significativa entre fungos quanto à severidade causada pela podridão de estacas de eucalipto foi observada por Paradela et al. (18), testando Botryosphaeria, Colletotrichum e Calonectria em um híbrido de $E$. grandis x E. urophylla. Uma explicação sobre a variação da patogenicidade entre os clones de acácia-negra, seria a variação da suscetibilidade do hospedeiro como no caso do patossistema Calonectria-Eucalyptus (3).

\section{Fonte de inóculo}

Fungos fitopatogênicos não foram encontrados nas minicepas. Nove gêneros de fungos foram isolados das brotações assintomáticas (Tabela 3), destacando-se C. polizzii. Em média, $40 \%$ das brotações assintomáticas apresentaram algum fungo, após 15 dias em câmara úmida e todas as brotações com lesões escuras, apresentaram C. polizzii. Em um híbrido de Eucalyptus grandis $x$ Eucalyptus urophylla, Paradela et al. (18) encontraram Cladosporium, Colletotrichum, Calonectria e Fusarium em estacas assintomáticas. Isolados desses gêneros também foram encontrados nesse trabalho. Brotações assintomáticas com lesões imperceptíveis a olho nu podem ser fontes de inóculo, pois após serem trazidas para a casa de vegetação as lesões se desenvolvem com posterior esporulação gerando esporos que serão disseminados a pequenas e longas distancias (7).

No caso dos tubetes lavados e usados, praticamente os mesmos fungos foram verificados, indicando falhas no processo de higienização e desinfestação desse material. Fusarium sp. e $N$. clavispora isolados

Tabela 2. Comprimento médio (mm) do apodrecimento das miniestacas e recuperação (\%) após sete dias da inoculação de Calonectria polizzii e Neopestalotiopsis clavispora.

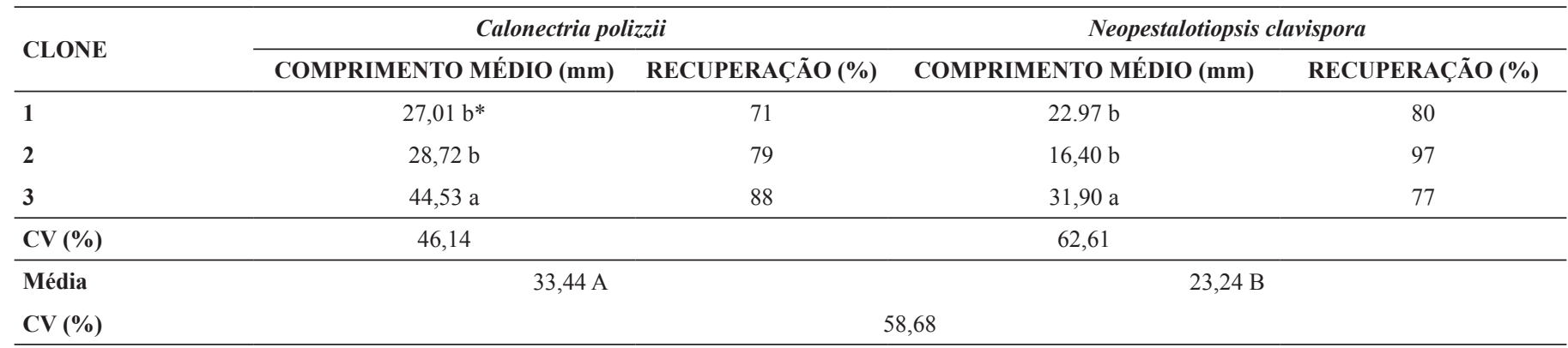

*Médias seguidas, por letras minúsculas distintas na coluna, e por letras maiúsculas distintas na linha, diferem entre si, pelo teste de Tukey, ao nível de 5 \% de significância. 
Tabela 3. Fungos encontrados em possíveis fontes de inóculo em viveiro da podridão de miniestacas de acácia-negra. Março/2016, Triunfo/RS.

\begin{tabular}{|c|c|c|c|c|}
\hline FUNGOS ENCONTRADOS & \multicolumn{4}{|c|}{ MATERIAL ANALISADO } \\
\hline Cladosporium sp. & + & - & - & - \\
\hline Calonectria polizzii & + & - & - & + \\
\hline Fusarium sp. & + & + & + & + \\
\hline Clonostachys sp. & + & + & + & + \\
\hline Phomopsis sp. & - & + & - & - \\
\hline Thielaviopsis sp. & + & + & + & - \\
\hline Trichoderma sp. & - & + & + & + \\
\hline Ulocladium sp. & - & + & - & - \\
\hline Verticillium $\mathrm{sp}$. & + & - & - & - \\
\hline
\end{tabular}
em que continha miniestaca com podridão; ${ }^{(4)}$ Britas coletadas do piso da estufa.

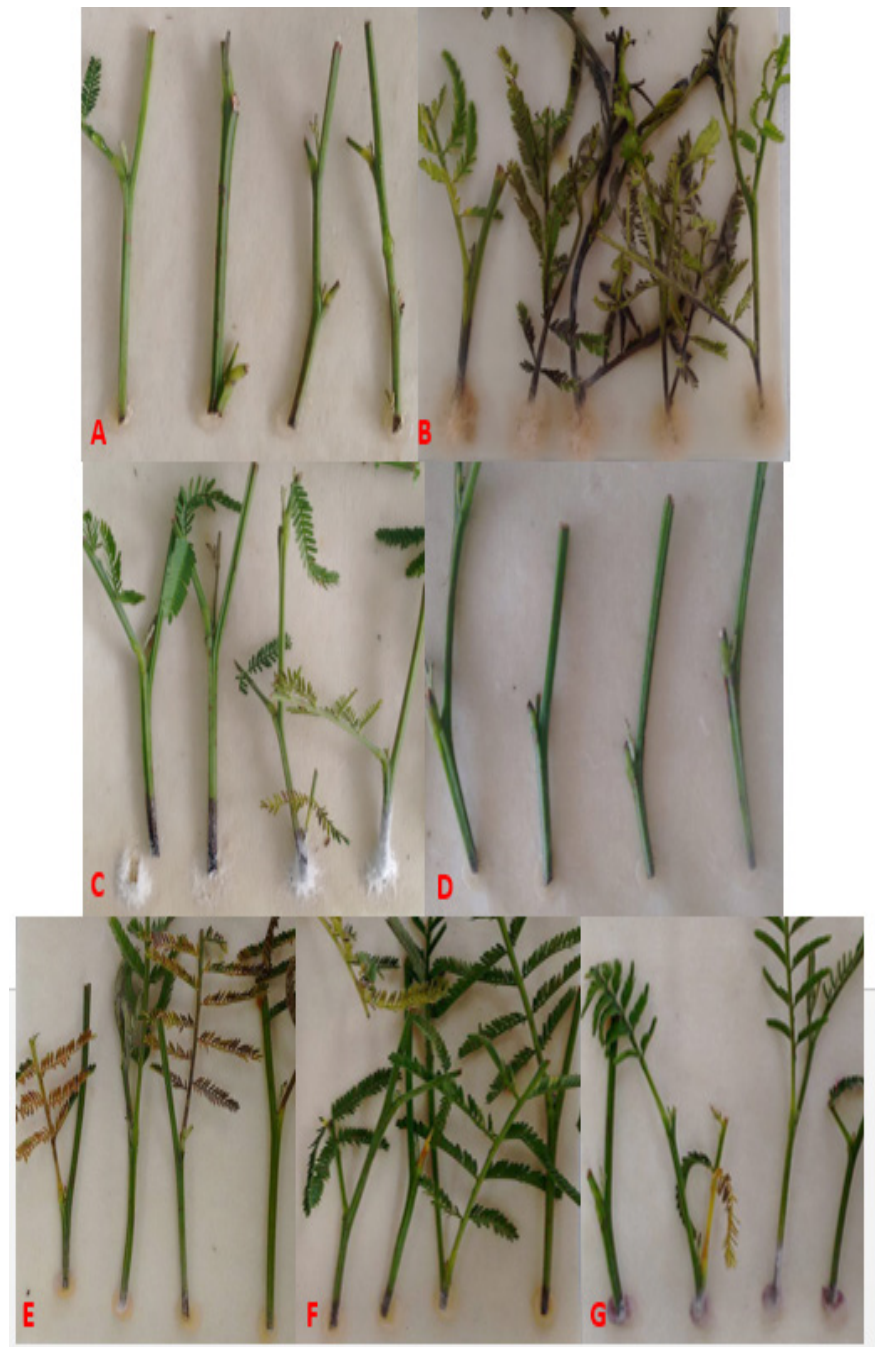

Figura 2. Teste de patogenicidade em miniestacas de acácia-negra. A: Miniestacas sem lesões (testemunha). B: Apodrecimento causado por Calonectria polizzii. C: Apodrecimento causado por Neopestalotiopsis clavispora. D: Miniestacas colonizadas por Rhizoctonia solani E: Miniestacas colonizadas por Fusarium oxysporum (1). F: Miniestacas colonizadas por Fusarium oxysporum (2). G: Miniestacas colonizadas por Fusarium sp. (3). de miniestacas com apodrecimento também foram isolados de tubetes, indicando que pode ser fonte de inóculo desses patógenos. Segundo Alfenas et al. (2), os tubetes devem ser previamente lavados com jatos de água sob pressão para remover ao máximo os resíduos de substrato e, posteriormente, devem ser desinfestados por imersão em água quente à $70^{\circ} \mathrm{C}$ por $3 \mathrm{~min}$ ou $80^{\circ} \mathrm{C}$ por $30 \mathrm{~s}$. Ainda segundo esses autores, a desinfestação térmica dos tubetes pode favorecer o aumento do índice de enraizamento e da massa do sistema radicular, provavelmente por eliminar substancias termolábeis que interferem na rizogênese. De acordo com o método utilizado no viveiro, pode ser que a limpeza dos tubetes não está sendo eficiente.

A presença de C. polizzii nas britas mostra o risco de disseminação desse fungo do piso da casa de vegetação para as miniestacas na mesa suspensa (11) e sua capacidade de sobreviver em vários ambientes (4), tornando em uma fonte de inóculo.

Com a técnica de diluição em série empregada para análise do substrato novo, da água e da areia, não se detectou algum fungo fitopatogênico. A ausência de C. polizzii no substrato novo mostra sua qualidade sanitária, reduzindo a possibilidade de servir como fonte de inóculo. Entretanto, no substrato usado este fungo foi constatado e não se recomenda a reutilização, pelo risco de reinfestação dos tubetes, da casa de vegetação e infectar as miniestacas sadias. Solo artificialmente infestado com Calonectria pode permanecer infestado por até sete meses (7).

De acordo com os resultados, Calonectria polizzii e Neopestalotiopsis clavispora são os agentes causais da podridão de miniestacas de acácianegra. Conclui-se, também, que brotações e miniestacas assintomáticas, tubetes, substratos usados e britas do piso da casa de vegetação podem ser fontes de inóculo desses patógenos indicando que medidas sanitárias devem ser aplicadas para impedir ou reduzir a podridão de miniestacas de acácia-negra.

\section{AGRADECIMENTOS}

Agradecemos à TANAC S.A. pelo apoio financeiro e técnico, à CAPES pela bolsa do primeiro autor, ao Laboratório de Patologia Florestal da UFLA, ao Laboratório de Patologia Básica da UFPR e Embrapa Florestas pelo apoio estrutural e técnico.

\section{REFERÊNCIAS}

1. Alfenas, A.C.; Ferreira, F.A.; Mafia, R.G.; Gonçalves, R.C. Isolamento 
de fungos fitopatogênicos. In: Alfenas, A.C.; Mafia, R.G. Métodos em Fitopatologia. Viçosa: Editora UFV, 2007. p. 53-91.

2. Alfenas, A.C.; Zauza, E.A.V.; Mafia, R.G.; Assis, T.F. Clonagem e doenças do eucalipto. 2.ed. Viçosa: Editora UFV, 2009. 500 p.

3. Altman, D.G. Practical statistics for medical research. London: Chapman \& Hall, 1991. 611 p.

4. Aparecido, C.C.; Finatti, D. Impacto do gênero Cylindrocladium para diferentes culturas. Comunicado técnico - Instituto Biológico, São Paulo, n. 176. 2012. Disponível em:<http://www.biologico.sp.gov.br/ artigos_ok.php?id_artigo=176>. Acesso em: 14 jun. 2017.

5. Auer, C.G.; Santos, A.F. dos. Principais doenças em viveiros de eucalipto. In: Dutra, L.F e Wendling, I. Produção de mudas de eucalipto. Colombo: Embrapa Florestas, 2010. 184 p.

6. Barnett, H.L.; Hunter, B.B. Illustrated genera of imperfect fungi. 3.ed. New York: MacMillan, 1972. 241 p.

7. Brown, B.N.; Ferreira, F.A. Disease during propagation of eucalypts. In: Keane, P.J.; Kile, G.A.; Podger, F.D e Brown, B.N. (Eds.) Disease and pathogens of eucalypts. Camberra: CSIRO Publishing, p. 119-151, 2000.

8. Cabel, S.R. Relações entre condições meteorológicas com a miniestaquia e a incidência de doenças bióticas em viveiro clonal de eucalipto no sul do Brasil. Curitiba, 2014. 73 p. Tese (Mestrado em Engenharia Florestal) - Universidade Federal do Paraná, Curitiba.

9. Carvalho, A.O.; Alfenas, A.C.; Demuner, N.L. Patogenicidade de fungos isolados de estacas de eucalipto para enraizamento, em casa de vegetação. Fitopatologia Brasileira, Brasília, v. 14, n.2, p. 122. 1989. (Resumo 055).

10. Disarz, R.; Corder, M.P.M. Multiplicação de gemas axilares de Acacia mearnsii De Wild. sob diferentes meios de cultura. Revista Árvore, Viçosa, v. 33, n. 4, p. 599-606, 2009.

11. Ferreira, F.A. Patologia florestal: principais doenças florestais no Brasil. Viçosa: Sociedade de Investigações Florestais, 1989. 570 p.

12. Ferreira, F.A.; Mendes, J.E.P.; Maia, J.L. Mortalidade de estacas enraizadas de Pinus spp. causada por Rhizoctonia solani. Fitopatologia brasileira, Brasília, v. 30, n. 2, p. 201-201, 2005.

13. Gonçalves, J. de L. Sazonalidade de ocorrência de mofo cinzento, oídio e manchas bacterianas foliares em dois viveiros de produção de mudas clonais de eucalipto. 2014. 41 f. Dissertação (Mestrado em Ciência Florestal) - Faculdade de Ciências Agronômicas - Universidade Estadual Paulista Faculdade de Ciências Agronômicas, Botucatu.

14. Marchiori, J.N.C. Dendrologia das angiospermas: leguminosas. Santa Maria: Editora UFSM, 1997. 200p.

15. Melo, I.S. Trichoderma e Gliocladium como bioprotetores de plantas. Revista Anual Patologia de Plantas, Passo Fundo. v. 4, n. 1, p. 261-295, 1996.

16. Mello, S.C.M. de; Reis, A.; Silva, J.B.T. da. Manual de curadores de germoplasma - micro-organismos: fungos filamentosos. Brasília: Embrapa Recursos Genéticos e Biotecnologia, 2011. 25 p.

17. Lombard, L.; Rodas, C.A.; Crous, P.W.; Wingfield, B.D.; Wingfield, M.J. Calonectria (Cylindrocladium) species associated with dying Pinus cuttings. In: Persoonia, Leiden, v. 23, p. 41-47, 2009.

18. Paradela, A.L.; Bedendo, I.P.; Krugner, T.L. Comunidade fúngica associada a brotações de Eucalyptus em jardim clonal e seu envolvimento na etiologia da podridão de estacas utilizadas para produção de mudas. Summa Phytopathologica, Jaguariúna, v.25, n.2, p.144-151, 1999.

19. Santos, A.F. dos; Grigoletti Júnior, A.; Auer, C.G.; Santana, D.L de. O complexo gomose da acacia-negra. Colombo: Embrapa Florestas, 2001. 8p.

20. Schultz, B. Levantamento de Doenças bióticas e abióticas em Eucalyptus benthamii Maiden nos Estados do Paraná e Santa Catarina. Curitiba, 2011. 101 p. Dissertação (Mestrado) - Universidade Federal do Paraná, Curitiba.

21. Silva, F.A.S.; Azevedo, C.A.V. The Assistat Software Version 7.7 beta and its use in the analysis of experimental data. African Journal of Agricultural Research. v. 11, n.39, p. 3733-3740, 2016. DOI: 10.5897/AJAR2016.11522.

22. Sotta, E.D.; Auer, C.G. Levantamento de fungos associados a gomose em acacia-negra. Colombo, PR: Embrapa-CNPF, 1995. 2p. (Embrapa-CNPF).

23. Sutton, B.C. The Coelomycetes: fungi imperfecti with pycnidia acervuli and stromata. Kew: CMI, 1980. 696 p.

24. Vitti, A.N.; Krügner, T.L.; Vieira, J.D. Etiologia da podridão de estacas de Eucalyptus spp. em casa de vegetação. Fitopatologia Brasileira, Brasília, v. 14, n.2, p. 126, 1989 (Resumo 083). 